\title{
Effect of GGBS Slag on Setting Time and Compressive Strength of One-Part Geopolymer Binders
}

\author{
Sani Haruna ${ }^{1,2)}$, Bashar S. Mohammed ${ }^{1)}$ \& M.M.A Wahab ${ }^{1)}$ \\ ${ }^{1)}$ Dept. of Civil \& Environmental Eng., Universiti Teknologi PETRONAS, Perak, Malaysia. \\ ${ }^{2)}$ Civil Engineering Department, Bayero University Kano, Kano, Nigeria.
}

Correspondent: sani_17000823@utp.edu.my

\begin{abstract}
This paper investigated the influence of ground granulated blast furnace slag (GGBS) on the setting time and compressive strength of one-part geopolymer binders (OPGB). Powdered sodium metasilicate activator was utilized in the range of $8-16 \%$ by weight of the total binder. The central composite design method was used in designing the mixtures. Experimental investigation revealed that both the initial and final setting times of the OPGB decreased drastically with the increase in the GGBS and the activator content. The inclusion of GGBS in the binder influences the setting time of the binders thereby resulting in quick setting time. The variance analysis of the established models demonstrated that the setting and compressive strength models could be predicted using quadratic models with a high $\mathrm{R}^{2}$ coefficient. Optimization results revealed that the optimum mixture can be obtained by substituting $95.8 \%$ fly ash with GGBS and $13.4 \%$ solid activator.
\end{abstract}

Keywords : One-part geopolymer, GGBS, Setting time, Compressive strength

\section{INTRODUCTION}

Sustainable cementing binder systems have been widely discussed and promoted as a component of the current and future toolkit (Provis 2018). Geopolymer is regarded as an encouraging sustainable and environmentally favorable material substitute to Portland cement in construction applications. Portland cement generation increments worldwide greenhouse gas emissions outflows through the calcination of clinker in hydrocarbon warmed heaters. Generally, a decrease in cement utilization has been accomplished by the utilization of industrial by-products, for example, fly ash and ground granulated blast furnace slag (GGBS) as partial or complete replacement materials to Portland cement in concrete. Nowadays, various regulatory standards of using alkali-activated materials have been proposed in a different part of the world, for small and large scale production (Shi et al 2003, Provis and Van Deventer 2013). The key motivation behind the recognition of alkali activation for more than a century of sporadic use was identified with the potential reduction of $\mathrm{CO}_{2}$ emissions when alkaliactivated materials are utilized instead of OPC based materials. Despite the numerous benefits possessed by geopolymer materials, the requirement for high temperature curing and dealing with a large volume of alkaline solutions makes it an issue for on-site applications. To address these problems, dry mixture is needed in such a way that only water will be added to the materials similar to that of OPC binders (Duxson \& Provis 2008, Nematollahi, Sanjayan, et al. 2015). Therefore, one-part geopolymers can be well suited for both in-situ and precast applications.

The production of one-part geopolymer consists of a dry mixture of a solid aluminosilicate precursor, and a solid alkali activator to which water is added, similar to the OPC preparation (Mohammed et al. 2019a, Mohammed et al. 2019b, Haruna et al. 2020). In 
practice, the setting time behavior of fresh binder is very vital as it determines the time allowed to transport, cast, and compact the one-part alkali-activated concrete. Abdel-Gawwad and AboEl-Enein (Abdel-Gawwad \& Abo-El-Enein 2016), have manufactured dry powder geopolymer cement similar to OPC. They have obtained an initial setting time of $23-49$ minutes and a final setting time of $60-98$ minutes. The setting time is shorter due to the presence of high calcium content in both the source material and the pulverized dry activator. Matalkah et al. (Matalkah et al 2016) have produced one-part geopolymer cement with an initial and final setting time of 38 and 210 minutes. The setting time of the developed one-part geopolymer cement for many concrete applications. According to Tennakoon et al. (Tennakoon et al 2016), the extra heat generated during the dissolution mechanism speeds up the setting time in anhydrous alkaliactivated one-part geopolymers relative to hydrated alkali-activated geopolymers. Their findings show that the primary factor contributing to the changes in the characteristics of fresh geopolymers produced with anhydrous sodium metasilicate and pentahydrate activators is the heat flow which is associated with the dissolution of solid activators. Apart from the obvious practical benefits of using solid activators, the type of solid activator allows the properties of the fresh binder to be adjusted.

Because of the heat released from the decomposition of solid activators, such as sodium hydroxide, one-part geopolymers have often been documented to quickly set (Suwan et al 2017). However, they have concluded that the setting times of the developed binders are suitable for many concrete applications (Matalkah et al 2016). Luukkonen et al. (Luukkonen et al 2018), have reported that the source of silica greatly affects the fresh properties of one-part alkali-activated GGBS mortar. The amount of silica composition in the precursor material and activator can easily adjust the setting time. The shortest setting times for the sodium metasilicate mixtures were observed, followed by the mixtures of RHA $+\mathrm{NaOH}$ and micro silica sand + $\mathrm{NaOH}$. They have also reported the initial setting time value of 20 to 70 minutes and final setting time of 30 to 220 minutes respectively. Depending on the strength class, the initial setting time needed for ordinary concrete was specified between 45-75 minutes (EN 2000). Although mixtures made with sodium metasilicate activator exhibit the shortest setting time, it demonstrated a very higher mechanical strength than the two mixtures. According to (Askarian et al 2018), one-part geopolymer concrete manufactured with low calcium fly ash and a small amount of slag as the binder did not harden within 24 hours after casting, this is attributed to the slow reactivity of the low calcium fly ash. However, incorporating OPC in the binder had significantly reduced both the initial and final setting times. They stated that the initial setting time varied from $86-11$ minutes, and the final setting between $139-53$ minutes for $10-70$ $\%$ OPC content in the binder.

Askarian et al. (Askarian et al 2018), have investigated the strength properties of ambient cured one-part hybrid OPC-geopolymer concrete. The study revealed that OPC content in the binder significantly affects the strength behavior of the one-part geopolymer at ambient curing regime. The strength improvement is more pronounced at the early age of 1 and 7 days, beyond 7 days of ambient curing, the strength continues to increase slowly as the OPC in the binder increases from $10-60$ percent of the total binder. The quick enhancement in strength at an early age was attributed to the fast reaction between OPC with the alkali activators. Sturm et al. (Sturm et al 2016), have produced a dry mixed geopolymer from rice husk ash (RHA). They have obtained a compressive strength of about $30 \mathrm{MPa}$ after 1 day of $80{ }^{\circ} \mathrm{C}$ oven curing. Hajimohammadi et al. (Hajimohammadi et al 2017), have also produced a one-part geopolymer binder using low calcium fly ash. They have achieved a high compressive strength of $65 \mathrm{MPa}$ after 3 weeks of curing at $40^{\circ} \mathrm{C}$. However, the requirements for oven curing make it unsuitable for cast-in-situ applications (Nurruddin et al 2018). Panda et al. (Panda et al 2019), have reported an increase in compressive strength of fly ash/ slag based OPG activated with solid potassium silicate for 3D concrete printing. The developed binder exhibited orthotropic 
mechanical properties. They have concluded that the developed binder can be used for loadbearing applications. Due to the layer-wise manufacturing strategy used in concrete printing, the printed geopolymers showed anisotropic mechanical efficiency relative to the mold cast samples. This investigation is aimed to evaluate the combined effect of solid sodium metasilicate activator and GGBS slag on the setting time and compressive strength of one-part geopolymer binders using response surface methodology (RSM). The research work will be useful for infrastructure management. Infrastructure management, among others, is about using better material for the economy and the sustainability of the infrastructures. That is why this research is important for infrastructure management (Suprayitno \& Soemitro 2018).

\section{MATERIALS AND EXPERIMENTAL METHODS}

\section{Materials}

Class C fly ash GGBS conforming with the requirements of ASTM C618-10 and ASTM C 989conforming have been utilized as the source materials in this investigation. Their oxide compositions were obtained by X-ray fluorescence (XRF) and presented in Table 1. Granular solid activator $\left(50 \%\right.$ of $\mathrm{Na}_{2} \mathrm{O}, 46 \%$ of $\mathrm{SiO}_{2}$, and $4 \%$ of $\left.\mathrm{H}_{2} \mathrm{O}\right)$ has been utilized as the activator. The granular activator has been used at $8-16 \%$ by weight of the total binder according to previous work by (Mohammed 2019).

Table 1. Oxide Composition of the source materials

\begin{tabular}{|c|c|c|}
\hline Oxide & Fly ash (\%) & GGBS (\%) \\
\hline $\mathrm{CaO}$ & 17.1 & 36.62 \\
\hline $\mathrm{Al}_{2} \mathrm{O}_{3}$ & 14.9 & 14.73 \\
\hline $\mathrm{SiO}_{2}$ & 37.3 & 33.86 \\
\hline $\mathrm{Fe}_{2} \mathrm{O}_{3}$ & 16.5 & 0.48 \\
\hline $\mathrm{MgO}$ & 3.72 & 6.33 \\
\hline $\mathrm{P}_{2} \mathrm{O}_{5}$ & 2.59 & - \\
\hline $\mathrm{SO}_{3}$ & 2.56 & 2.10 \\
\hline $\mathrm{Na}_{2} \mathrm{O}$ & 1.74 & 0.16 \\
\hline $\mathrm{K}_{2} \mathrm{O}$ & 1.66 & 0.39 \\
\hline $\mathrm{TiO}_{2}$ & 1.07 & 0.73 \\
\hline Others & 0.69 & 1.13 \\
\hline LOI & 0.17 & 1.72 \\
\hline
\end{tabular}

\section{Development of response surface models}

Response surface methodology is a statistical tool typically utilized to model and optimizes experimental mixtures in geopolymer and (OPC) production (Mermerdaş 2017, Mohammed 2017, Haruna Sani 2018). The RSM analysis includes various designs that can be used to generate statistical correlations between responses and independent parameters. The most commonly used design methods in the field of civil engineering are Box-Behnken design (BBD) and central composite design (CCD). Design expert software has been used for experimental designs and optimizations. The optimization process involves three major steps: (1) conducting the statistically designed experimental work, (2) predicting the coefficients in a 
mathematical model, and (3) predicting the model's response and verifying its adequacy (Mohammed 2012, Sadhukhan 2016). In this investigation, two independent variables consisting of sodium metasilicate activator and GGBS have been used to design the experimental mixtures. The details of the experimental work are shown in Table 2. The five duplications are the key points the program uses to enhance the accuracy of the experiment against any possible errors.

Table 2. Experimental design parameters

\begin{tabular}{|c|c|c|c|c|c|}
\hline \multirow{2}{*}{ Run } & \multicolumn{2}{|c|}{ Coded level (\%) } & \multicolumn{2}{c|}{ Actual values } & \\
\cline { 2 - 6 } & $\begin{array}{c}\text { A: sodium } \\
\text { metasilicate }\end{array}$ & B: GGBS & $\begin{array}{c}\text { A: sodium } \\
\text { metasilicate } \\
(\%)\end{array}$ & $\begin{array}{c}\text { B: GGBS } \\
(\%)\end{array}$ & w/s ratio \\
\hline 1 & 1 & 0 & 16 & 50 & 0.25 \\
\hline 2 & 0 & 0 & 12 & 50 & 0.25 \\
\hline 3 & 0 & 0 & 12 & 50 & 0.25 \\
\hline 4 & 1 & 1 & 16 & 100 & 0.25 \\
\hline 5 & 0 & 0 & 12 & 50 & 0.25 \\
\hline 6 & 1 & -1 & 16 & 0 & 0.25 \\
\hline 7 & 0 & -1 & 12 & 0 & 0.25 \\
\hline 8 & 0 & 1 & 12 & 100 & 0.25 \\
\hline 9 & -1 & 0 & 8 & 50 & 0.25 \\
\hline 10 & 0 & 0 & 12 & 50 & 0.25 \\
\hline 11 & 0 & 0 & 12 & 50 & 0.25 \\
\hline 12 & -1 & -1 & 8 & 0 & 0.25 \\
\hline 13 & -1 & 1 & 8 & 100 & 0.25 \\
\hline
\end{tabular}

\section{Preparation of one-part geopolymer binders and test methods}

The mixing of one-part geopolymer binders has been carried out using a Hobart mortar mixer in compliance with the standard procedure of ASTM C305-14. The preparation of onepart geopolymer binders involves the blending of the precursor materials with granular sodium metasilicate activator for about 3 minutes to obtain a uniform dry geopolymer binder. Progressively, clean tap water was injected into the dry mixture and stirred for another 3 minutes until it becomes homogeneous and consistent. The mixing has been carried out in a laboratory at approx. $25^{\circ} \mathrm{C}$. To evaluate the influence of solid activator and GGBS dosage on setting time, the Vicat apparatus has been utilized to conduct the setting time measurement of one-part geopolymer binders as per ASTM C807. Digital compressive strength testing equipment was used in determining the compressive strength of the developed OPGB.

\section{RESULT AND DISCUSSION}

\section{Effect of GGBS and activator on initial setting time}

The influence of GGBS and sodium metasilicate activator on the initial setting time of one-part geopolymer paste is shown in Figure 1. As illustrated in Figure 1, the 3D response surface diagram for initial setting time concerning two independent variables (anhydrous sodium metasilicate activator and GGBS) on initial setting time. It can be observed that the initial setting time decreases with an increasing dosage of sodium metasilicate activator and GGBS content. Incorporating GGBS in the binder plays a vital role in decreasing the setting time of the binder. This is attributed to the presence of high calcium oxide in the system and high specific surface area of the slag particles. To quantify the relationship between one or more 
measured responses with the independent variables contour plots was used. Figure 1(b) shows that the entire contour lines were semi-elliptical in shape, which suggests a great relationship between the GGBS and the solid activator. It can be observed that both the dosage of the activator and GGBS significantly affect the initial setting time of the OPGP. Additionally, the greenish - bluish portion on the 2D plot indicates a region of optimum initial setting time while the bluish region in the contour diagram represents the region with the lowest initial setting time. At this region prolonging the mixing time of the binder will make the paste harden in the bowl of the mixer which can make it impossible to cast in the respective molds.
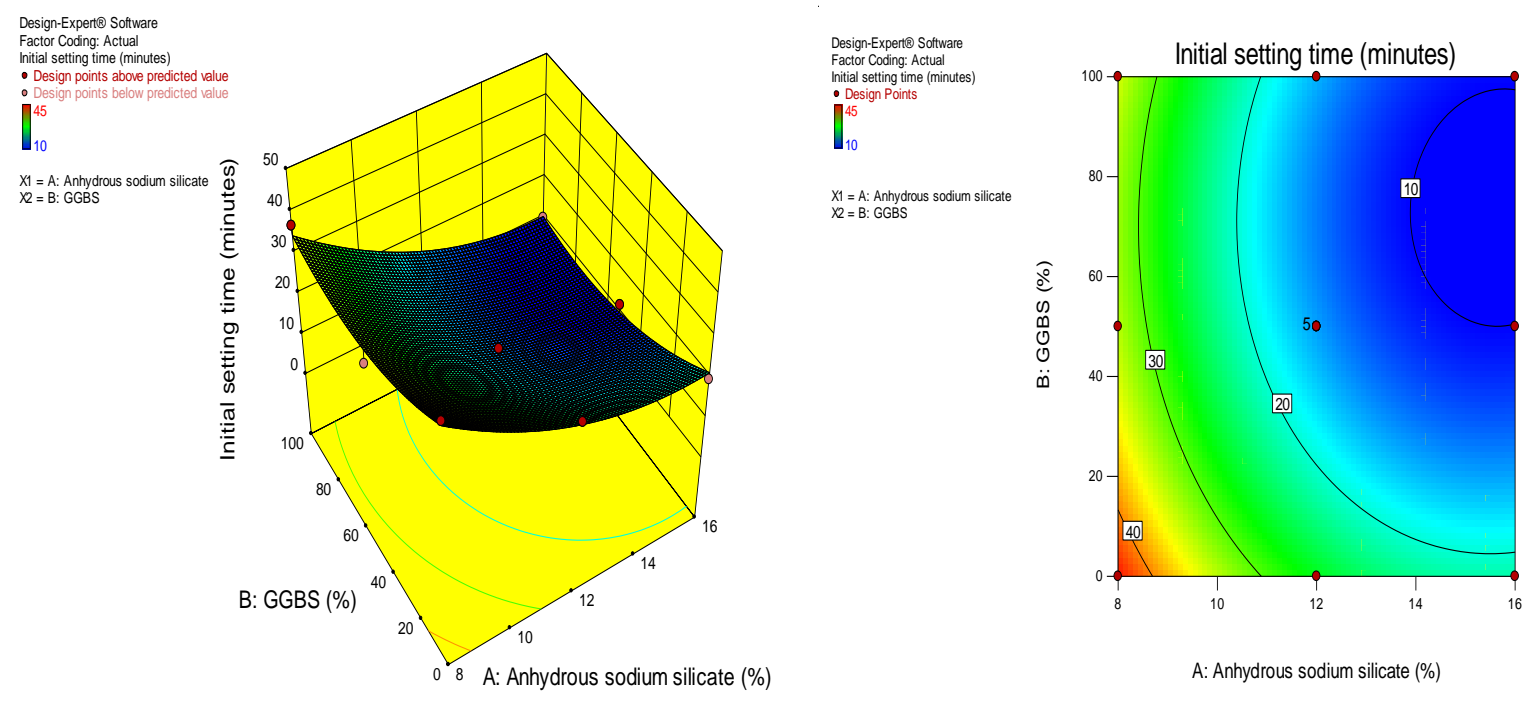

Figure 1. Initial setting time response surface plots (a) 3-D surface plot (b) 2-D contour plot

\section{Effect of GGBS and activator on final setting time}

The 3-dimensional response surface diagram showing the effects of the independent variables on the final setting time of the developed OPGP is shown in Figure 2. It has been noted that the 3D surface diagram showed that all the variables have affected the final setting time significantly. As shown in Figure 2, the final setting time decreased with an increase in both the anhydrous sodium metasilicate activator and the GGBS. This could be correlated with the heat generated by the dissolution of solid activator resulting in quick setting time of the binder. The existence of high calcium in the GGBS coupled with high specific surface area in the binder tends to absorb more water in the mixture and consequently decreased the final setting time of the mixtures. The 2 - dimensional contour plots for the final setting time model for fly ash/GGBS OPGB is shown in Figure 2(b), the entire contour curves were oval, implying an optimal relationship between the GGBS and solid activator. The bluish regions on the contour plots indicate the region of the shortest final setting time of the OPGB while the reddish-yellowish portion indicates a portion of relatively higher final setting time. 

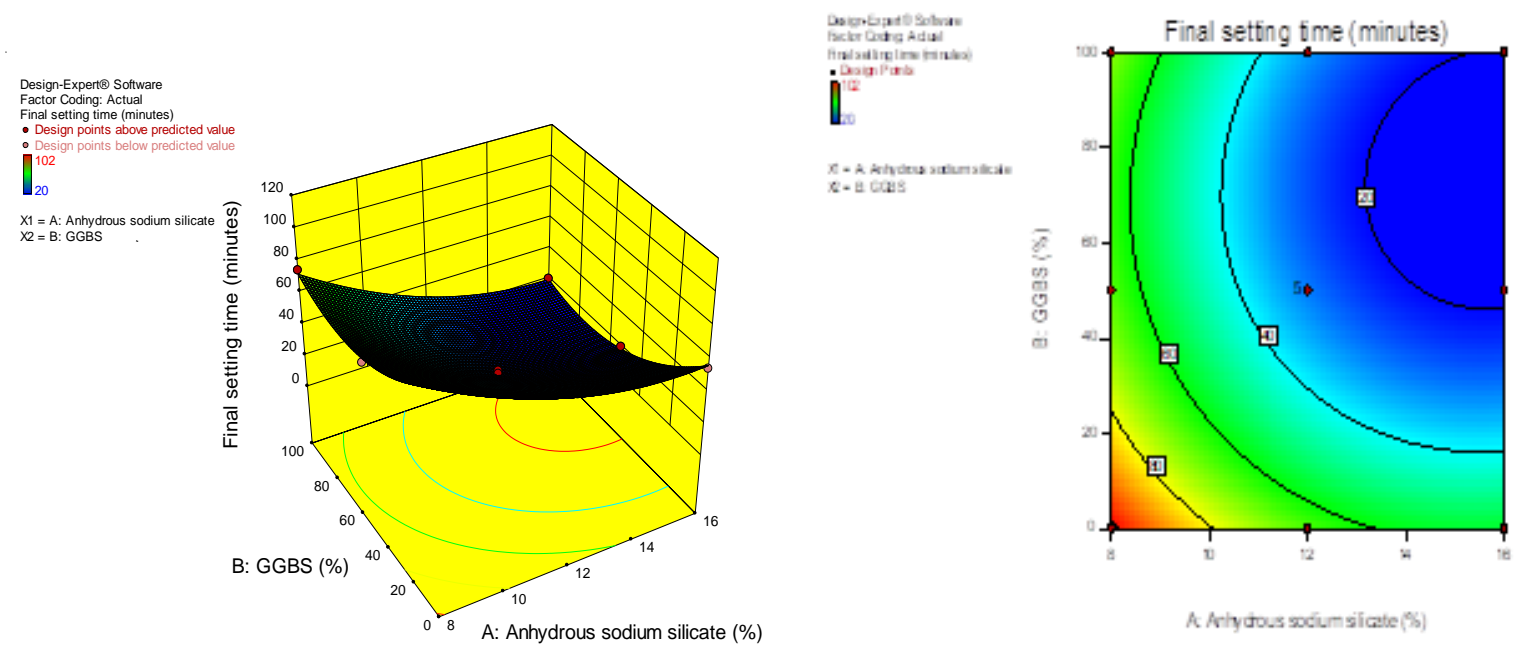

Figure 2. Final setting time response surface plots (a) 3-D surface plot (b) 2-D contour plot

\section{Effect of GGBS and activator on compressive strength}

The compressive strength of the developed OPGP enhanced significantly with increased in the activator dosage and GGBS content as shown in Figure 3. The 3-D diagram gives more detail on the interaction between the independent variables on compressive strength. The addition of GGBS in the mixture improved the strength of the developed binders significantly. This is attributed to the formation of the dense microstructure of the binder due to the presence of calcium aluminosilicate hydrate gel (C-A-S-H). This leads to an enhancement of the compressive strength of the binder. activated. However, minor cracks were noticed on the surface of the mixtures with high GGBS. The cracks were associated with the heat released during the dissolution of the solid activator.
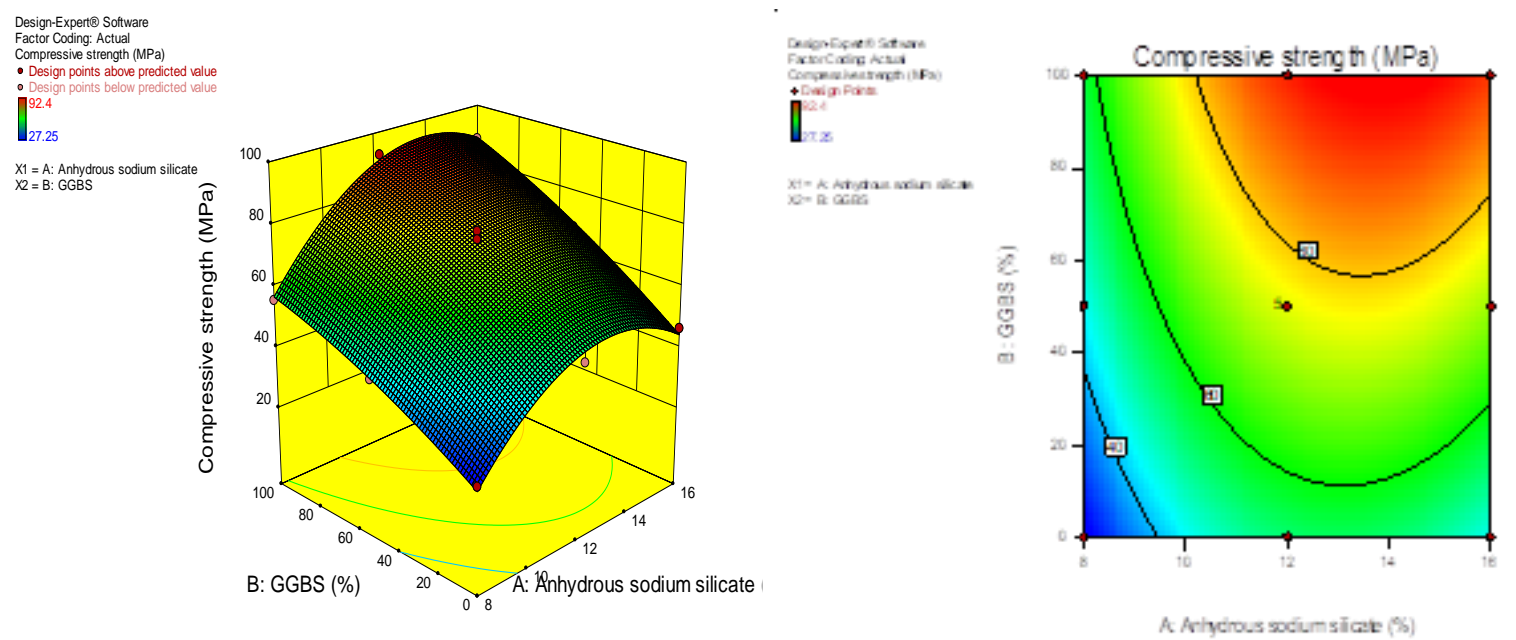

Figure 3. Compressive strength response surface diagrams (a) 3-D surface plot (b) 2-D contour plot

\section{Analysis of variance for the response models developed}

After performing the regression analysis. The fitted quadratic model was developed for the prediction of all the response models. The models were chosen based on the highest order 
polynomial in which the additional terms were significant and not aliased by the software. The summary of the analysis of variance for response surface quadratic models for the initial setting, final setting time, and compressive strength is shown in Table 3. As presented in Table 3, the initial setting time, final setting time and compressive strength response models have a high Fvalue of 49.96, 286.32, and 167.29 which implied that the model is statistically significant and there is only $0.01 \%$ chance that an F-value of that large could occur due to noise. The significance of the model and all the model terms were evaluated using a t-test at $5 \%$ significance level $(\mathrm{P}<0.05)$ (Sani Haruna 2020). For all the response models, model terms of P-Values less than 0.05 implies that the terms are statistically significant, while model terms of P-values $>0.05$ indicate that the terms were insignificant. For the model to be statistically fit, the P-value for the lack of fit must be greater than 0.05 . For this response, P-values of 0.0665 , $0.0775,0.1329$ indicate that all the response models have good fitness.

Table 3. Variance analysis for the models established

\begin{tabular}{|c|c|c|c|c|c|c|}
\hline \multirow{2}{*}{ Terms } & \multicolumn{2}{|c|}{ Initial setting time } & \multicolumn{2}{c|}{ Final setting time } & \multicolumn{2}{c|}{ Compressive strength } \\
\cline { 2 - 7 } & F-Value & P-Value & F-Value & P-Value & F-Value & P-Value \\
\hline Model & 49.96 & $<0.0001$ & 286.32 & $<0.0001$ & 167.29 & $<0.0001$ \\
\hline $\mathrm{A}$ & 154.89 & $<0.0001$ & 665.45 & $<0.0001$ & 183.92 & $<0.0001$ \\
\hline $\mathrm{B}$ & 30.38 & 0.0009 & 307.95 & $<0.0001$ & 410.48 & $<0.0001$ \\
\hline $\mathrm{AB}$ & 0.19 & 0.6763 & 2.96 & 0.1292 & 8.55 & 0.0222 \\
\hline $\mathrm{A}^{2}$ & 21.55 & 0.0024 & 89.24 & $<0.0001$ & 170.87 & $<0.0001$ \\
\hline $\mathrm{B}^{2}$ & 18.32 & 0.0037 & 198.53 & $<0.0001$ & 5.46 & 0.0521 \\
\hline Lack of fit & 5.50 & 0.0665 & 4.98 & 0.0775 & 3.42 & 0.1329 \\
\hline
\end{tabular}

Where A: Sodium metasilicate activator, B: GGBS slag

The quality and adequacy of the developed models were examined based on its correlation coefficient $\mathrm{R}^{2}$. Table 4 presents the fit statistic values for all the response models. All the responses have high $\mathrm{R}^{2}$ values which are almost 1 , thus indicating that the experimental results are well correlated by the models. A high $\mathrm{R}^{2}$ value close to 1 is ideal for a good model, with a fair agreement with modified $\mathrm{R}^{2}$ (Mohammed (2020). The adjusted $\mathrm{R}^{2}$ is a modified form of $\mathrm{R}^{2}$ which has been modified for the number of predictors in the model. The predicted $\mathrm{R}^{2}$ values of all the response models were in good agreement with their corresponding adjusted $\mathrm{R}^{2}$ values as the difference between them is less than 0.2. The signal to noise ratio of the model is estimated based on adequate precision (AP). For a model to be adequate, an AP value greater than 4 is generally desirable for a good model (Montgomery 2017, Mohammed 2018, Khed 2020). In this investigation, the AP values for all the developed models were found to be greater than 4 . This indicates that all the models are desirable, adequate, and could be used to navigate the design space. 
Table 4. Model validation

\begin{tabular}{|c|c|c|c|c|}
\hline Response models & $\mathrm{R}^{2}$ & Adj. $\mathrm{R}^{2}$ & Pred. $\mathrm{R}^{2}$ & $\mathrm{AP}$ \\
\hline Initial setting time & 0.9727 & 0.9533 & 0.7764 & 21.740 \\
\hline Final setting time & 0.9951 & 0.9917 & 0.9601 & 52.763 \\
\hline Compressive strength & 0.9917 & 0.9858 & 0.9399 & 41.925 \\
\hline
\end{tabular}

The final empirical model in terms of the actual variables for the initial setting time, final setting time, and compressive strength response models with all the model terms are given in Eqn. 1, 2, and 3.

$$
\begin{aligned}
& T_{i s}=+119.115-12.537 \mathrm{~A}-0.340 \mathrm{~B}+0.401 \mathrm{~A}^{2}+0.002 \mathrm{~B}^{2} \\
& \mathrm{~T}_{\mathrm{fs}}=+252.701-25.461 \mathrm{~A}-1.002 \mathrm{~B}-0.01 \mathrm{AB}+0.827 \mathrm{~A}^{2}+0.008 \mathrm{~B}^{2} \\
& \mathrm{~F}_{\mathrm{C}}=-136.308+29.238 \mathrm{~A}+0.306 \mathrm{~B}+0.017 \mathrm{AB}-1.121 \mathrm{~A}^{2}-0.001 \mathrm{~B}^{2}
\end{aligned}
$$

Where $T_{\text {is }}$ is the initial setting time in minutes, $T_{\text {fs }}$ final setting time in minutes, $F_{c}$ compressive strength in MPa, A is the sodium metasilicate activator (\%), and B is the GGBS $(\%)$.

The predicted against actual was used to illustrates the fitness and degree of precision for the model developed. The distribution of the points along the straight line in Figure 4 shows a reasonable fitting accuracy of the models and the actual result and predicted results agreed with each other. To avoid repetition only one response is considered.

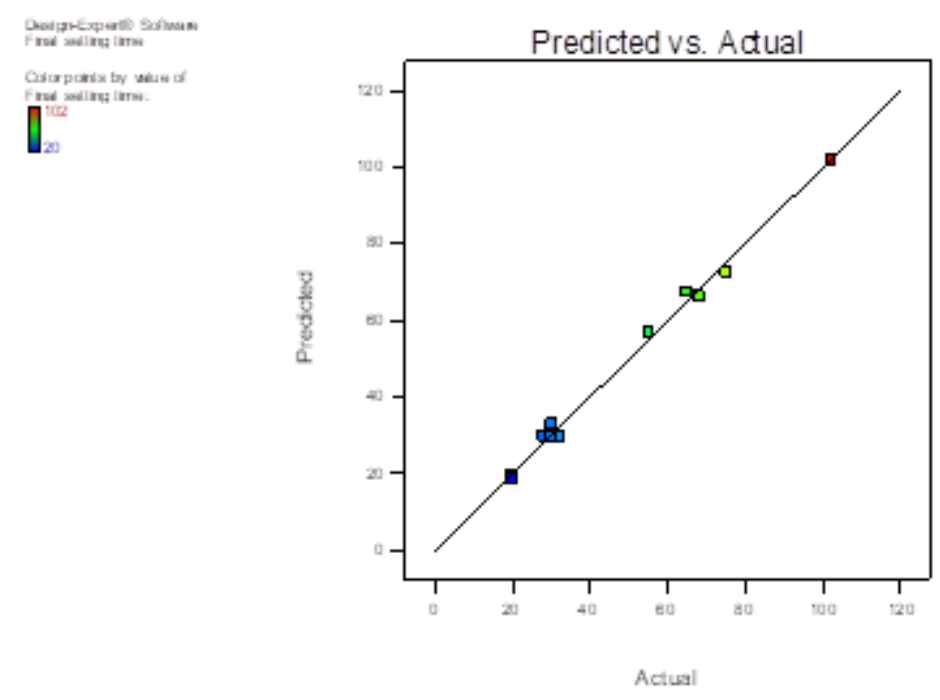

Figure 4. Predicted Vs actual plot of the developed models

\section{Numerical optimization}

The optimization process concentrates on pinpointing the preferred values of the independent variables to obtain the optimum composition of the solid activator and GGBS that could give the highest strength. Based on the optimization criteria, the optimum desired mixture fractions of $95.81 \%$ of GGBS with $13.4 \%$ of anhydrous sodium metasilicate were suggested by 
the RSM software with unified desirability of $100 \%$. The optimization outcome of the developed models was illustrated by a 3 - D surface graph shown in Figure 5.

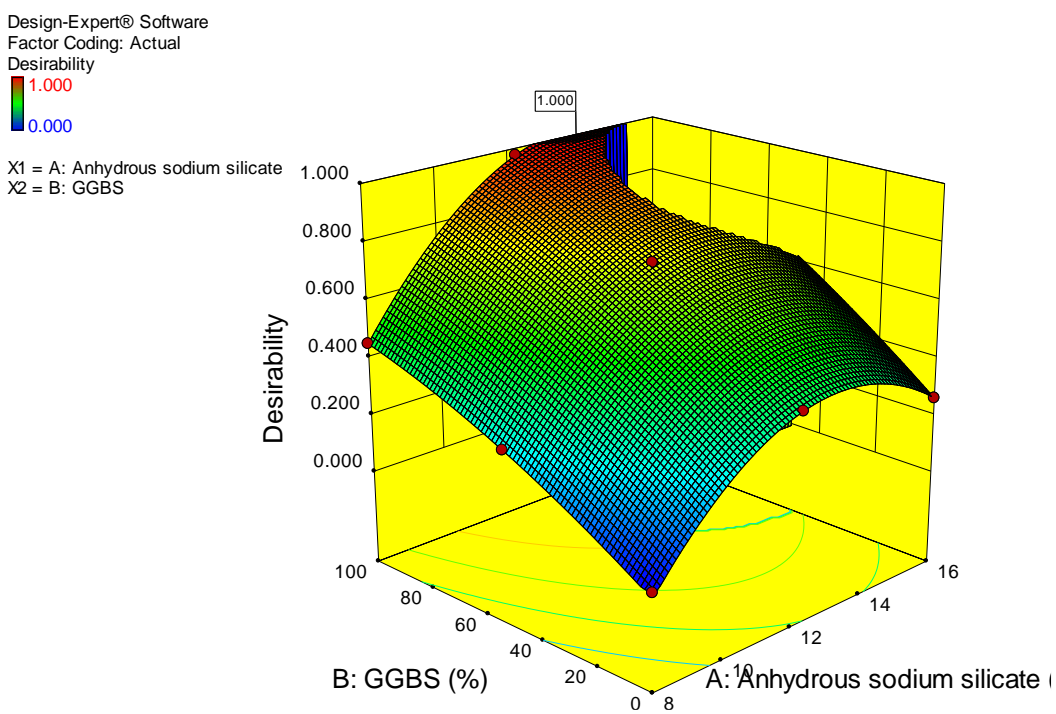

Figure 5. 3-D optimum desirability response surface plot.

\section{CONCLUSION}

The influence of two independent variables (anhydrous sodium metasilicate activator and the percentage replacement of fly ash with GGBS) on the setting time, and compressive strength of one-part geopolymer binders were evaluated with the help of response surface methodology (RSM). Based on the experimental work performed in this study, the following findings could be highlighted:

1. Experimental study shows that both the initial and final setting times of the one-part geopolymer paste decreased drastically with the increase in the GGBS and the activator content.

2. The presence of GGBS in the mixtures significantly enhanced the compressive strength of the one-part geopolymer binders. Few microcracks appeared when GGBS was used as the sole precursor.

3. The ultimate result of the RSM optimization process proves that the forecasted results are well associated with the observational data.

4. The verification results were very proximate to the experimental outcomes. The optimization process revealed that the best mixture proportion could be achieved by utilizing $95.8 \%$ GGBS in the binder with $13.4 \%$ solid activator.

\section{REFERENCES}

Abdel-Gawwad, H., and S. Abo-El-Enein (2016). "A novel method to produce dry geopolymer cement powder." HBRC Journal 12(1): 13-24.

Askarian, M., Tao, Zhong, Adam, Georgius, Samali, Bijan (2018). "Mechanical properties of ambient cured one-part hybrid OPC-geopolymer concrete." Construction and Building Materials 186: 330-337.

Duxson, P. and J. L. Provis (2008). "Designing precursors for geopolymer cements." Journal of the American Ceramic Society 91(12): 3864-3869.

EN, B. (2000). "Cement-Part 1: Composition, specifications and conformity criteria for common cements." British Standards Institution 197-1. 
Hajimohammadi, A., van Deventer, Jannie SJ (2017). "Characterisation of one-part geopolymer binders made from fly ash." Waste biomass valorization 8(1): 225-233.

Haruna Sani, M. B. S., Liew, M.S, Alaloul Wessam Salah, Haruna Abdulrahman (2018). "Effect of water-binder ratio and NAOH molarity on the properties of high calcium fly ash geopolymer mortars at outdoor curing." International Journal of Civil Engineering \& Technology 9(10): 1339-1352.

Khed, V. C., Mohammed, Bashar S., Liew, M. S., Abdullah Zawawi, Noor Amila Wan (2020). "Development of response surface models for self-compacting hybrid fibre reinforced rubberized cementitious composite." Construction and Building Materials 232: 117191.

Luukkonen, T., Abdollahnejad, Zahra, Yliniemi, Juho, Kinnunen, Paivo, Illikainen, Mirja (2018). "Comparison of alkali and silica sources in one-part alkali-activated blast furnace slag mortar." Journal of Cleaner Production 187: 171-179.

Matalkah, F., Xu, Liwei, Wu, Wenda, Soroushian, Parviz (2016). "Mechanochemical synthesis of one-part alkali aluminosilicate hydraulic cement." Materials and Structures 50(1): 97.

Mermerdaş, K., Algın, Zeynep, Oleiwi, Safie Mahdi, Nassani, Dia Eddin (2017). "Optimization of lightweight GGBFS and FA geopolymer mortars by response surface method." Construction and Building Materials 139: 159-171.

Mohammed, B. S., Achara, Bitrus Emmanuel, Nuruddin, Muhd Fadhil, Yaw, Melvin, Zulkefli, Mohd Z (2017). "Properties of nano-silica-modified self-compacting engineered cementitious composites." Journal of cleaner production 162: 1225-1238.

Mohammed, B. S., Fang, Ong Chuan, Anwar Hossain, Khandaker M., Lachemi, Mohamed (2012). "Mix proportioning of concrete containing paper mill residuals using response surface methodology." Construction and Building Materials 35: 63-68.

Mohammed, B. S., Haruna, Sani, Wahab, M. M. A. Liew, M. S. Haruna, Abdulrahman (2019). "Mechanical and microstructural properties of high calcium fly ash one-part geopolymer cement made with granular activator." Heliyon 5(9): e02255.

Mohammed, B. S., Khed, Veerendrakumar C., Liew, Mohd Shahir (2018). "Optimization of hybrid fibres in engineered cementitious composites." Construction and Building Materials 190: 24-37.

Mohammed, B. S., Xian, Lee Wei, Haruna, Sani, Liew, MS, Abdulkadir, Isyaka, Zawawi, Nor Amila Wan Abdullah (2020). "Deformation Properties of Rubberized Engineered Cementitious Composites Using Response Surface Methodology." Iranian Journal of Science and Technology, Transactions of Civil Engineering: 1-12.

Montgomery, D. C. (2017). Design and analysis of experiments._John Wiley \& Sons.

Nematollahi, B., J. Sanjayan and F. U. A. Shaikh (2015). "Synthesis of heat and ambient cured one-part geopolymer mixes with different grades of sodium silicate." Ceramics International 41(4): 5696-5704.

Nurruddin, M. F., Haruna, Sani, Mohammed, Bashar S, Sha'aban, Ibrahim Galal (2018). "Methods of curing geopolymer concrete: A review." International Journal of Advanced and Applied Sciences 5(1): 31-36.

Panda, B., Singh, G. V. P. Bhagath, Unluer, Cise, Tan, Ming Jen (2019). "Synthesis and characterization of one-part geopolymers for extrusion based 3D concrete printing." Journal of Cleaner Production 220: 610-619.

Provis, J. L. (2018). "Alkali-activated materials." Cement and Concrete Research 114: 40-48.

Provis, J. L. and J. S. Van Deventer (2013). Alkali activated materials: state-of-the-art report, RILEM TC 224-AAM, Springer Science \& Business Media.

Sadhukhan, B., Mondal, Naba K., Chattoraj, Soumya (2016). "Optimisation using central composite design (CCD) and the desirability function for sorption of methylene blue from aqueous solution onto Lemna major." Karbala International Journal of Modern Science 2(3): $145-155$. 
Sani Haruna, B. S. M., Mohamed Mubarak bn Abdul Wahab, Abdulrahman Haruna (2020). "Compressive strength and workability of High Calcium One-Part alkali activated mortars using response surface methodology " IOP Conference Series: Earth and Environmental Science 2nd International Conference on Civil and Environmental Engineering, Langkawi, Kedah, Malaysia. 476.

Shi, C., Roy, Della, Krivenko, Pavel (2003). Alkali-activated cements and concretes. CRC Press.

Sturm, P. G., G. J. G, Brouwers, H. J. H, Kühne, H. C. (2016). "Synthesizing one-part geopolymers from rice husk ash." Construction and Building Materials 124: 961-966.

Suprayitno, Hitapriya \& Soemitro, Ria Asih Aryani (2018). "Preliminary Reflexion on Basic Principle of Infrastructure Asset Management". Jurnal Manajemen Aset Infrastruktur \& Fasilitas, 2(1), Maret 2020, Hal. 1-10.

Suwan, T. F., Mizi (2017). "Effect of manufacturing process on the mechanisms and mechanical properties of fly ash-based geopolymer in ambient curing temperature." Materials and Manufacturing Processes 32(5): 461-467.

Tennakoon, C., Nicolas, Rackel San, Sanjayan, Jay G., Shayan, Ahmad (2016). "Thermal effects of activators on the setting time and rate of workability loss of geopolymers." Ceramics International 42(16): 19257-19268. 
e)ISSN 2656-8896 (p)ISSN 2656-890X

Journal of Infrastructure and Facility Asset Management - Vol. 2, Issue. 2, September 2020 